\title{
Phylogeny of the genus Simonsiella and other members of the Neisseriaceae
}

Department of Microbiology, University of Washington, Box 357242 Seattle, WA 98195-7242, USA

\author{
Brian P. Hedlundt and James T. Staley \\ Author for correspondence: Brian P. Hedlund. Tel: +49941943 3144. Fax: +499419432403. \\ e-mail: brian.hedlund@biologie.uni-regensburg.de
}

Keywords: Simonsiella, phylogeny, Neisseriaceae, horizontal gene transfer

\section{INTRODUCTION}

Simonsiella is a morphologically unique oral commensal of mammals. Individual cells of Simonsiella are wide $(1.9-6.4 \mu \mathrm{m})$, short $(0.5-1.3 \mu \mathrm{m})$ and relatively flat $(0.5-1.3 \mu \mathrm{m})$, and attach to form monoseriate filaments that are 8-12 cells long. Filaments are bent slightly to form a watchband-like shape and show dorsal-ventral asymmetry. The ventral surface is covered with thin filaments that protrude at right angles from the cells (Pangborn et al., 1977). This surface attaches to and glides on epithelial cells in the oral cavity and upper respiratory tract of the host.

Simonsiella-like bacteria have been reported in many animals including humans, horses, cows, pigs, sheep, dogs, rabbits, cats, guinea pigs and chickens (Kuhn, 1981). However, few studies have resulted in the isolation and detailed study of axenic Simonsiella cultures. A notable exception was the work by Kuhn et al. (1978), which entailed the collection of over 50 Simonsiella strains from humans, sheep, dogs and cats. A numerical taxonomic study showed that most of the Simonsiella strains grouped according to the mammalian host from which they were isolated. Simonsiella

Published online ahead of print on 14 December 2001 as DOI 10.1099/ ijs.0.01952-0.

†Present address: c/o Professor $\mathrm{Dr}$ K. O. Stetter, Lehrstuhl für Mikrobiologie, Universität Regensburg, Universitätsstraße 31, D-93053 Regensburg, Germany.

The GenBank/EMBL/DDBJ accession numbers for the Simonsiella 16S rDNA sequences reported in this study are AF328141-AF328156. isolates from humans and sheep were each monophyletic in a dendrogram derived from the numerical taxonomy data. Isolates from cats and dogs tended to cluster together with strains from the same host; however, neither group was strictly monophyletic based on phenotypic data. These observations led to the proposal that each of these mammals has a unique type of Simonsiella (Kuhn et al., 1978). The authors suggested that these host groups represented ecospecies: species of bacteria that each occupied a niche in a unique ecosystem, the mouths of different animals. Accordingly, three of the Simonsiella groups were assigned to separate species. Simonsiella muelleri, Simonsiella crassa and Simonsiella steedae were proposed for Simonsiella strains native to humans, sheep and dogs, respectively; however, the cat Simonsiella isolates remained unnamed.

The higher-order taxonomy of Simonsiella has been a confusing subject. Steed (1962) designated the family Simonsiellaceae to include Simonsiella and the superficially similar genus Alysiella; however, the genus Alysiella has been reported to be unrelated to Simonsiella (Stackebrandt et al., 1988). Dewhirst et al. (1989) sequenced 16S rRNA from the type strain of $S$. muelleri and found that it clustered within the Neisseriaceae in the $\beta$-Proteobacteria. Appropriately, the authors emended the family Neisseriaceae to include Simonsiella.

Since only one Simonsiella strain has been included in published molecular phylogenetic studies, and those studies were restricted to distance analyses that were 
Table 1. Sources, $16 \mathrm{~S}$ rDNA accession numbers and references for strains and 16S rDNA sequences used in the study

Culture collections are abbreviated as: Bangor, A. J. Howard, Ysbyty Gwynedd, Bangor LL57 2PW, UK; CCUG, Dept of Clinical Microbiology, University of Göteborg, Göteborg, Sweden; CDC, Centers for Disease Prevention and Control, Atlanta, GA, USA; FDC, Forsyth Dental Center, Boston, MA, USA; LCDC, Laboratory Centre for Disease Control, Ottawa, Canada K1A 0L2; NCTC, L. R. Hill, National Collection of Type Cultures, London NW9 5EQ, UK; NRL, Neisseria Reference Laboratory, US Public Health Service Hospital, Seattle, WA 98114, USA.

\begin{tabular}{|c|c|c|}
\hline Strain & Accession no. & Reference \\
\hline Escherichia coli & J01695 & Brosius et al. (1978) \\
\hline \multicolumn{3}{|l|}{ Eikenella corrodens } \\
\hline ATCC $23834^{\mathrm{T}}$ & M22512 & Dewhirst et al. (1989) \\
\hline FDC 373 & M22513 & Dewhirst et al. (1989) \\
\hline FDC 1073 & M22515 & Dewhirst et al. (1989) \\
\hline Eikenella sp. CCUG 28283 & L06165 & Dewhirst et al. (1989) \\
\hline \multicolumn{3}{|l|}{ Kingella denitrificans } \\
\hline ATCC $33394^{\mathrm{T}}$ & M22516 & Dewhirst et al. (1989) \\
\hline CCUG 28284 (=UB-294) & L06166 & Dewhirst et al. (1993) \\
\hline Kingella kingae ATCC $23330^{\mathrm{T}}\left(=\mathrm{Y}^{\mathrm{T}}\right)$ & M22517 & Dewhirst et al. (1989) \\
\hline Kingella oralis ATCC $51147^{\mathrm{T}}\left(=\mathrm{CCUG} 30450^{\mathrm{T}}\right)$ & L06164 & Dewhirst et al. (1993) \\
\hline Neisseria animalis ATCC $19573^{\mathrm{T}}\left(=\mathrm{C}^{\mathrm{T}}\right)$ & L06172 & Dewhirst et al. (1993) \\
\hline Neisseria canis ATCC $14687^{\mathrm{T}}\left(=\mathrm{D} 1^{\mathrm{T}}=\mathrm{D} 1 \mathrm{a}^{\mathrm{T}}\right)$ & L06170 & Dewhirst et al. (1993) \\
\hline Neisseria cinerea ATCC $14685^{\mathrm{T}}\left(=\mathrm{F} 1^{\mathrm{T}}=\mathrm{NCTC} 10294^{\mathrm{T}}\right)$ & AJ239299 & Smith et al. (1999) \\
\hline Neisseria denitrificans ATCC $14686^{\mathrm{T}}\left(=\mathrm{H} 1^{\mathrm{T}}=\mathrm{H} 1 \mathrm{a}^{\mathrm{T}}\right)$ & L06173 & Dewhirst et al. (1993) \\
\hline Neisseria elongata ATCC $25295^{\mathrm{T}}$ & L06171 & Dewhirst et al. (1993) \\
\hline Neisseria elongata & - & $\begin{array}{l}\text { F. E. Dewhirst and others, } \\
\text { personal communication }\end{array}$ \\
\hline Neisseria flavescens ATCC $13120^{\mathrm{T}}$ & L06168 & Dewhirst et al. (1993) \\
\hline \multicolumn{3}{|l|}{ Neisseria gonorrhoeae } \\
\hline 76993 & AF146369 & $\begin{array}{l}\text { D. Raoult and others, } \\
\text { personal communication }\end{array}$ \\
\hline ATCC $19424^{\mathrm{T}}\left(=\mathrm{NCTC} 83785^{\mathrm{T}}=\mathrm{A} 59^{\mathrm{T}}=\mathrm{A} 59 \mathrm{a}^{\mathrm{T}}\right)$ & X07714 & Rossau et al. (1990) \\
\hline \multicolumn{3}{|l|}{ Neisseria lactamica } \\
\hline LCDC 77-143 (= L17) & AJ239313 & Smith et al. (1999) \\
\hline $\operatorname{LCDC} 845(=\mathrm{L} 19)$ & AJ239296 & Smith et al. (1999) \\
\hline Neisseria macacae ATCC $33926^{\mathrm{T}}\left(=\mathrm{W} 1^{\mathrm{T}}=\mathrm{W} 1 \mathrm{a}^{\mathrm{T}}\right)$ & L06169 & Dewhirst et al. (1993) \\
\hline Neisseria mucosa Bangor 15 (= M5) & AJ239279 & Smith et al. (1999) \\
\hline Neisseria perflava $\mathrm{U} 15$ & AJ239295 & Smith et al. (1999) \\
\hline ‘Neisseria pharyngis’ NCTC $4590(=\mathrm{O} 4)$ & AJ239281 & Smith et al. (1999) \\
\hline Neisseria polysaccharea ATCC $43768^{\mathrm{T}}\left(=\mathrm{P} 5^{\mathrm{T}}=\mathrm{P}^{\mathrm{T}}=\mathrm{CCUG} 18030^{\mathrm{T}}\right)$ & L06167 & Dewhirst et al. (1993) \\
\hline \multicolumn{3}{|l|}{ Neisseria sicca } \\
\hline LCDC R9742 (= Q13) & AJ239292 & Smith et al. (1999) \\
\hline $\operatorname{ATCC} 49276^{\mathrm{T}}\left(=\mathrm{Q} 29^{\mathrm{T}}=\mathrm{Q} 29 \mathrm{a}^{\mathrm{T}}=\mathrm{NRL} 30016^{\mathrm{T}}\right)$ & AJ239294 & Smith et al. (1999) \\
\hline Neisseria subflava NRL $30017^{\mathrm{T}}\left(=\mathrm{U} 37^{\mathrm{T}}=\mathrm{U} 37 \mathrm{a}^{\mathrm{T}}\right)$ & AJ239291 & Smith et al. (1999) \\
\hline Neisseria weaveri CDC 8142 & L10738 & Andersen et al. (1993) \\
\hline \multicolumn{3}{|l|}{ Simonsiella crassa } \\
\hline ATCC $27504 *$ & AF328141 & This study \\
\hline ATCC 29446 & AF328142 & This study \\
\hline ATCC 29447 & AF328143 & This study \\
\hline ATCC 29448 & AF328144 & This study \\
\hline \multicolumn{3}{|l|}{ Simonsiella muelleri } \\
\hline ATCC 29433 & AF328145 & This study \\
\hline ATCC 29441 & AF328146 & This study \\
\hline ATCC $29453^{\mathrm{T}}$ & AF328147 & This study \\
\hline ATCC 29462 & AF328148 & This study \\
\hline \multicolumn{3}{|l|}{ Simonsiella steedae } \\
\hline ATCC $27409^{\mathrm{T}}$ & AF328153 & This study \\
\hline ATCC 29435 & AF328154 & This study \\
\hline ATCC 29445 & AF328155 & This study \\
\hline ATCC 29457 & AF328156 & This study \\
\hline
\end{tabular}


Table 1 (cont.)

\begin{tabular}{|clc|}
\hline Strain & Accession no. & Reference \\
\hline Simonsiella sp. & & This study \\
ATCC 27381 & AF328152 & This study \\
ATCC 29436 & AF328149 & This study \\
ATCC 29437 & AF328150 & This study \\
ATCC 29465 & AF328151 \\
\hline
\end{tabular}

* Strain ATCC 27504 is a second deposition of the type strain of $S$. crassa, ATCC $15533^{\mathrm{T}}$.

not evaluated by tree-validation techniques such as bootstrap replications (Dewhirst et al., 1989, 1993), several questions concerning Simonsiella evolution remain. These questions include: (i) is the genus Simonsiella monophyletic?; (ii) is the integrity of the three Simonsiella species supported by molecular data?; and (iii) what is the relationship between the Simonsiella isolates from cats and the other Simonsiella species? To test the current Simonsiella species groupings and determine the diversity of the group within the context of other bacteria, 16S rDNA from 16 representative Simonsiella strains was sequenced and analysed. In the process, the phylogeny of the Neisseriaceae in general was examined.

\section{METHODS}

Bacterial strains. Simonsiella strains were donated from the American Type Culture Collection (ATCC, Manassas, VA, USA) and propagated on modified trypticase soy medium (ATCC medium 646), which contains $\left(1^{-1}\right): 17 \cdot 0 \mathrm{~g}$ trypticase (BBL 11921), 3.0 g phytone (BBL 11906), $5 \cdot 0 \mathrm{~g} \mathrm{NaCl}, 2 \cdot 5 \mathrm{~g}$ $\mathrm{K}_{2} \mathrm{HPO}_{4}$ and $4.0 \mathrm{~g}$ yeast extract. After the medium was autoclaved and cooled to $50{ }^{\circ} \mathrm{C}$, fetal bovine serum was added to a final concentration of $10 \%(\mathrm{v} / \mathrm{v})$ to supply growth factors. Strain designations, sources and accession numbers are shown in Table 1.

16S rDNA PCR and sequencing. Genomic DNA was isolated using the Instagene kit (Bio-Rad). 16S rDNA was amplified by PCR using bacterial primers (Reysenbach et al., 1994) and the following parameters: 32 cycles of $1.5 \mathrm{~min}$ at $94{ }^{\circ} \mathrm{C}$, $1 \mathrm{~min}$ at $42{ }^{\circ} \mathrm{C}$ and $4 \mathrm{~min}$ at $72{ }^{\circ} \mathrm{C}$; the last step of the last cycle was extended to $10 \mathrm{~min}$. The product was purified using commercial columns (Ultrafree MC; Millipore) and sequenced using the Big Dye Terminator Cycle Sequencing kit (Applied Biosystems) and 16S rDNA-specific forward and reverse primers (Dyksterhouse et al., 1995). Sequence contigs were created manually in the SeqApp data editor (Gilbert, 1992). Reference sequences were obtained from the National Center for Biological Information (NCBI) or from the Ribosomal Database Project (RDP; Maidak et al., 1999).

Sequence alignment and phylogenetic analysis. The prealigned sequences from the 'Sequence Alignments' archive of the 'Download' section of the RDP web site were used as an alignment template. Simonsiella sequences and sequences obtained from the NCBI were aligned using the RDP
'Sequence Aligner' program in the 'Online Analyses' section of the RDP web site or were aligned manually. The alignment was checked manually in GeneDoc (K. Nicholas \& H. Nicholas; http://www.psc.edu/biomed/genedoc/). As recommended by Kishino \& Hasegawa (1989) and others, positions containing gaps were removed. However, it is noteworthy that analyses done without removing positions that contained gaps produced results that were similar to those obtained with gaps removed. The final alignment consisted of 1313 positions, encompassing Escherichia coli positions 28-1425 (Brosius et al., 1978). It consisted of many members of the Neisseriaceae (Table 1) and 20 members of the $\gamma$ - and $\beta$-Proteobacteria, which served as outgroup taxa.

For likelihood, an alignment was initially analysed using DNAPARS (Felsenstein, 1993) and MACCLADE (Maddison \& Maddison, 1992) to determine empirically the transition to transversion (Ts/Tv) ratio and nucleotide base frequencies. Using DNAPARS, the alignment was analysed (random sequence input order and 10 subreplicates) and the single most parsimonious result was imported into MACCLADE, where the 'State Changes and Stasis' command was used to determine the Ts/Tv ratio of $1 \cdot 8$. This value and the base frequencies were specified in DNAML analyses.

For parsimony and distance analyses, 10 alignments, consisting of randomly chosen taxa from the original alignment, were created. The alignments were analysed using PAUP (Swofford, 1998) and TreEcon (Van de Peer \& De Watcher, 1994) for parsimony (random input order and 10 subreplicates) and distance (Kimura correction, neighbour-joining) analyses, respectively. The tree in Fig. 1 was projected using TREECON.

\section{RESULTS AND DISCUSSION}

Members of the genus Simonsiella possess a morphology that is both striking and unique among the Bacteria. For this reason, it would seem likely that they would make up a coherent phylogenetic group that excluded other bacteria. To test this hypothesis, the phylogeny of Simonsiella and representatives of the genera Kingella, Eikenella and Neisseria was addressed using maximum-likelihood, parsimony and distance methods. However, the resulting phylogeny depended on the phylogenetic method and on the particular taxa that were included. Significantly, bootstrap support values for any particular relationship between Simonsiella strains from different hosts were low, except those grouping the cat and dog isolates. Some analyses 


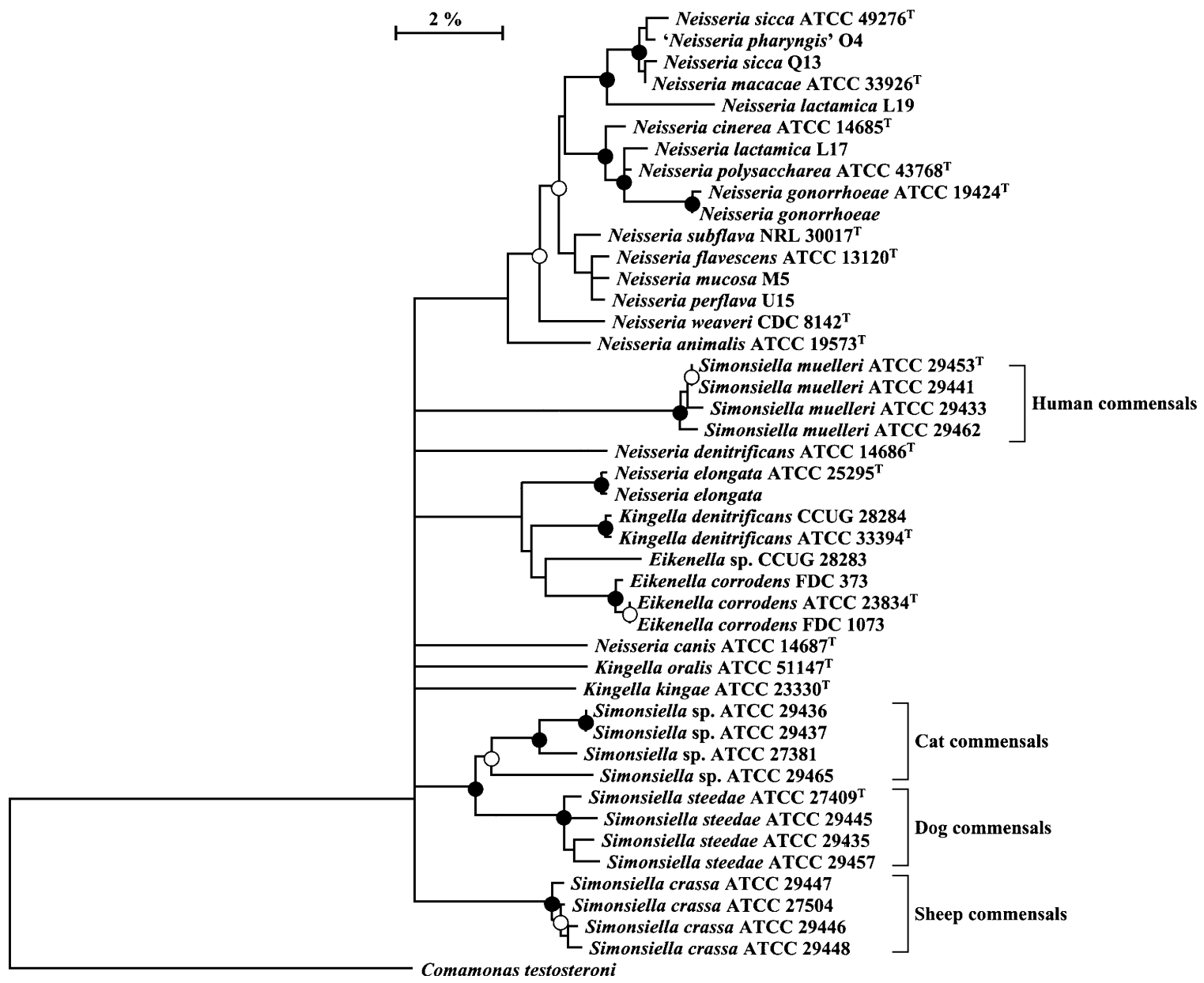

Fig. 1. Consensus neighbour-joining tree. 0 , Nodes with $>90 \%$ bootstrap support for all analyses; $\bigcirc$, nodes with $>75 \%$ bootstrap support; nodes with $<50 \%$ support are shown as unresolved. Bar, approx. $2 \%$ nucleotide divergence.

showed S. muelleri branching with Neisseria denitrificans. A phylogenetic relationship between $S$. muelleri and $N$. denitrificans was supported by relatively high $16 \mathrm{~S}$ rDNA similarity levels $(96 \cdot 4-96 \cdot 6 \%)$ and was presented previously by Dewhirst et al. $(1989,1993)$. However, in other analyses, no specific relationship between $S$. muelleri and $N$. denitrificans was implied (data not shown). Bootstrap support for a relationship between $S$. muelleri and $N$. denitrificans was never higher than $65 \%$ (data not shown). Fig. 1 shows a majority-rule tree. Since the Simonsiella strains belonged to three lineages whose relationship to each other and to other Neisseriaceae lineages is uncertain, the analyses failed to support or reject the hypothesis that the genus Simonsiella had a monophyletic origin.

It is possible that the genus Simonsiella had a monophyletic origin and that $16 \mathrm{~S}$ rDNA evidence of the monophyly of the group was lost. Discrepancies abound between $16 \mathrm{~S}$ rDNA phylogenies of the genus Neisseria and those derived from analyses of other loci (Smith et al., 1999) or from chemotaxonomic data (Barrett \& Sneath, 1994). Smith et al. (1999) suggested that the anomalies were due to interspecies gene exchange. Consistent with this hypothesis, the authors discussed phylogenetic evidence that certain Neisseria $16 \mathrm{~S}$ rDNA sequences are hybrids. Furthermore, it is well known that members of the genus Neisseria are competent; documented examples of transformation and recombination between Neisseria species are ample in the literature, even when donor and recipient differ by as much as $25 \%$ in their DNA $\mathrm{G}+\mathrm{C}$ content (Zhou \& Spratt, 1992; Feil et al., 1996; Zhou et al., 1997). Thus, members of the genus Neisseria could have acquired and recombined with Simonsiella $16 \mathrm{~S}$ rDNA sequences. It is not known whether Simonsiella themselves are competent; if they are, then horizontal gene transfer from Neisseria or other oral flora to Simonsiella could have added to the confusion.

However, it cannot be ruled out that the genus Simonsiella is polyphyletic. The ancestor of the Neisseriaceae could have been morphologically like modern Simonsiella. Loss of Simonsiella morphology and gliding motility could have occurred independently several times, giving rise to Kingella, Eikenella and multiple groups of Neisseria. Alternatively, the distinctive Simonsiella morphology could have arisen 
repeatedly in the Neisseriaceae. Indeed, no phenotypic traits of Simonsiella, other than morphology and motility, are known to be unique among the Neisseriaceae. Given the horizontal gene transfer activity of this family, the question of Simonsiella monophyly may never be answered convincingly.

Although the monophyly of the genus Simonsiella could not be established, Simonsiella groups that corresponded to the mammalian host from which they were isolated were clearly delineated. Three of the four host groups were supported by $100 \%$ of bootstrap replications. These corresponded to the existing Simonsiella species, $S$. muelleri, $S$. steedae and $S$. crassa, which are respectively commensals of humans, dogs and sheep. The fourth group, comprising Simonsiella isolates from domestic cats, was more phylogenetically diverse than the other groups (Fig. 1). Nevertheless, this group was monophyletic in maximum-likelihood analyses and in $\geqslant 82 \%$ of all bootstrap replications for distance and parsimony analyses, regardless of the particular taxa that were analysed (data not shown). Thus, our analyses strengthen Kuhn's division of Simonsiella into ecospecies. The explanation for this pattern of Simonsiella diversity is not clear; however, it is intriguing to speculate whether the divergence of Simonsiella into host-specific ecospecies was forced by speciation events of Simonsiella hosts. Circumstantial evidence in support of this possibility is that all analyses, phylogenetic (Fig. 1) and phenotypic (Kuhn et al., 1978), support a relationship between $S$. steedae and the cat Simonsiella isolates. Domestic dogs and cats both belong to the order Carnivora and are thought to have diverged about 45 million years ago (Kumar \& Hedges, 1998), whereas the last common ancestors of the carnivores and humans or sheep are thought to have existed 80-100 million years ago (Kumar \& Hedges, 1998). Examining phylogenetic relationships between Simonsiella isolates from a group of mammals whose evolution is well understood could test the hypothesis that Simonsiella co-diverged with their hosts. If a coevolutionary relationship could be confirmed between Simonsiella and its hosts, it would provide a unique opportunity to compare bacterial species with mammalian species that have existed for the same length of time. Such a situation could provide information that could be used to evaluate the current bacterial species concept.

The phylogenetic and ecological distinctness of Kuhn's cat Simonsiella isolates suggest that they may represent a distinct species. This notion is also supported by the fact that the cat Simonsiella isolates each differ from their closest relatives, members of $S$. steedae, by more than $2.5 \%$ in their $16 \mathrm{~S}$ rDNA sequences (Stackebrandt $\&$ Goebel, 1994). However, the most deeply branching of these strains, ATCC 29465 (Fig. 1), did not cluster with the other cat Simonsiella isolates in Kuhn's taxonomy study, differing from the others in its ability to reduce nitrate and in containing some fatty acid signatures typical of S. steedae (Jenkins et al., 1977).
Also, the cat Simonsiella isolates are phenotypically similar to S. steedae. Thus, a decision on the whether a novel species designation is warranted for the cat Simonsiella strains will depend on DNA-DNA hybridization data.

\section{ACKNOWLEDGEMENTS}

We thank Cheryl Jenkins and Jeremy Dodsworth for comments and discussions. Additionally, we thank the American Type Culture Collection for kindly providing the Simonsiella strains used in this study. The primary author was supported by the Helen Riaboff Whiteley Endowment and the Public Health Service, National Research Service Award, T32 GM07270, from the National Institute of General Medical Sciences.

\section{REFERENCES}

Andersen, B. M., Steigerwalt, A. G., O'Connor, S. P., Hollis, D. G., Weyant, R. S., Weaver, R. E. \& Brenner, D. J. (1993). Neisseria weaveri sp. nov., formerly CDC group M-5, a Gram-negative bacterium associated with dog bite wounds. J Clin Microbiol 31, 2456-2466.

Barrett, S. J. \& Sneath, P. H. A. (1994). A numerical phenotypic taxonomic study of the genus Neisseria. Microbiology 140, 2867-2891.

Brosius, J., Palmer, M. L., Kennedy, P. J. \& Noller, H. F. (1978). Complete nucleotide sequence of a $16 \mathrm{~S}$ ribosomal RNA gene from Escherichia coli. Proc Natl Acad Sci U S A 75, 4801-4805.

Dewhirst, F. E., Paster, B. J. \& Bright, P. L. (1989). Chromobacterium, Eikenella, Kingella, Neisseria, Simonsiella, and Vitreoscilla species comprise a major branch of the beta group Proteobacteria by $16 \mathrm{~S}$ ribosomal ribonucleic acid sequence comparison: transfer of Eikenella and Simonsiella to the family Neisseriaceae (emend.). Int J Syst Bacteriol 39, 258-266.

Dewhirst, F. E., Chen, C.-K. C., Paster, B. J. \& Zambon, J. J. (1993). Phylogeny of species in the family Neisseriaceae isolated from human dental plaque and description of Kingella orale sp. nov. Int J Syst Bacteriol 43, 490-499.

Dyksterhouse, S. E., Gray, J. P., Herwig, R. P., Lara, J. C. \& Staley, J. T. (1995). Cycloclasticus pugetii gen. nov., sp. nov., an aromatic hydrocarbon-degrading bacterium from marine sediments. Int $J$ Syst Bacteriol 45, 116-123.

Feil, E., Zhou, J., Maynard Smith, J. \& Spratt, B. G. (1996). A comparison of the nucleotide sequences of the $a d k$ and $\operatorname{rec} A$ genes of pathogenic and commensal Neisseria species: evidence for extensive interspecies recombination within adk. J Mol Evol 43, 631-640.

Felsenstein, J. (1993). PHYLIP (phylogenetic inference package) version 3.5.1. Department of Genetics. University of Washington, Seattle, USA. http://evolution.genetics.washington.edu/phylip.html

Gilbert, D. G. (1992). SEQAPP 1.9a169, a biological sequence editor and analysis program for Macintosh computers. http://iubio.bio.indiana. edu

Jenkins, C. L., Kuhn, D. A. \& Daly, K. R. (1977). Fatty acid composition of Simonsiella strains. Arch Microbiol 113, 209-213.

Kishino, H. \& Hasegawa, M. (1989). Evaluation of the maximum likelihood estimate of the evolutionary tree topologies from DNA sequence data, and the branching order in Hominoidea. J Mol Evol 29, 170-179.

Kuhn, D. A. (1981). The genera Simonsiella and Alyssiella In The Prokaryotes, pp. 390-399. Edited by M. P. Starr, H. Stolp, H. G. Trüper, A. Balows \& H. G. Schlegel. New York: Springer.

Kuhn, D. A., Gregory, D. A., Buchanan, G. E., Jr, Nyby, M. D. \& Daly, K. R. (1978). Isolation, characterization, and numerical taxonomy of Simonsiella strains from the oral cavities of cats, dogs, sheep, and humans. Arch Microbiol 118, 235-241.

Kumar, S. \& Hedges, S. B. (1998). A molecular timescale for vertebrate evolution. Nature 392, 917-920. 
Maddison, W. P. \& Maddison, D. R. (1992). MACCLADE: analysis of phylogeny and character evolution, version 3.03. Sunderland, MA: Sinauer Associates.

Maidak, B. L., Cole, J. R., Parker, C. T., Jr \& 11 other authors (1999). A new version of the RDP (Ribosomal Database Project). Nucleic Acids Res 27, 171-173.

Pangborn, J., Kuhn, D. A. \& Woods, J. R. (1977). Dorsal-ventral differentiation in Simonsiella and other aspects of its morphology and ultrastructure. Arch Microbiol 113, 197-204.

Reysenbach, A.-L., Wickham, G. S. \& Pace, N. R. (1994). Phylogenetic analysis of the hyperthermophilic pink filament community in Octopus Spring, Yellowstone National Park. Appl Environ Microbiol 60, 2113-2119.

Rossau, R., Duhamel, M., Van Dyck, E., Piot, P. \& Van Heuverswyn, H. (1990). Evaluation of an rRNA-derived oligonucleotide probe for culture confirmation of Neisseria gonorrhoeae. J Clin Microbiol 28 , 944-948.

Smith, N. H., Holmes, E. C., Donovan, G. M., Carpenter, G. A. \& Spratt, B. G. (1999). Networks and groups within the genus Neisseria: analysis of $\arg F, \operatorname{rec} A$, rho, and 16S rRNA sequences from human Neisseria species. Mol Biol Evol 16, 773-783.

Stackebrandt, E. \& Goebel, B. M. (1994). Taxonomic note: a place for DNA-DNA reassociation and 16S rRNA sequence analysis in the present species definition in bacteriology. Int $J$ Syst Bacteriol 44, 846-849.

Stackebrandt, E., Murray, R. G. E. \& Trüper, H. G. (1988). Proteobacteria classis nov., a name for the phylogenetic taxon that includes the "purple bacteria and their relatives". Int J Syst Bacteriol 38, 321-325.

Steed, P. D. M. (1962). Simonsiellaceae fam. nov. with characterization of Simonsiella crassa and Alysiella filiformis. J Gen Microbiol 29, 615-624.

Swofford, D. L. (1998). PAUP*. Phylogenetic analysis using parsimony (*and other methods), version 4. Sunderland, MA: Sinauer Associates.

Van de Peer, Y. \& De Wachter, R. (1994). TREECON for Windows: a software package for the construction and drawing of evolutionary trees for the Microsoft Windows environment. Comput Appl Biosci 10,569-570.http://www.evolutionsbiologie.uni-konstanz.de/peer-lab/ treeconw.html

Zhou, J. \& Spratt, B. G. (1992). Sequence diversity within the $\arg F$, $f b p$, and recA genes of natural isolates of Neisseria meningiditis: interspecies recombination within the $\arg F$ gene. Mol Microbiol 6, 2135-2146.

Zhou, J., Bowler, L. D. \& Spratt, B. G. (1997). Interspecies recombination, and phylogenetic distortions, within the glutamine synthetase and shikimate dehydrogenase genes of Neisseria meningiditis and commensal Neisseria species. Mol Microbiol 23, 799-812. 